\title{
The Tausk Controversy on the Foundations of Quantum Mechanics: Physics, Philosophy, and Politics
}

\author{
Osvaldo Pessoa, Jr., Olival Freire, Jr., and Alexis De Greiff*
}

In 1966 the Brazilian physicist Klaus Tausk (b. 1927) circulated a preprint from the International Centre for Theoretical Physics in Trieste, Italy, criticizing Adriana Daneri, Angelo Loinger, and Giovanni Maria Prosperi's theory of 1962 on the measurement problem in quantum mechanics. A heated controversy ensued between two opposing camps within the orthodox interpretation of quantum theory, represented by Léon Rosenfeld and Eugene P. Wigner. The controversy went well beyond the strictly scientific issues, however, reflecting philosophical and political commitments within the context of the Cold War, the relationship between science in developed and Third World countries, the importance of social skills, and personal idiosyncrasies.

Key words: Klaus S. Tausk; Adriana Daneri; Angelo Loinger; Giovanni Maria Prosperi; Piero Caldirola; Niels Bohr; Léon Rosenfeld; Werner Heisenberg; John von Neumann; Eugene Wigner; Josef Maria Jauch; David Bohm; Jeffrey Bub; Abdus Salam; Mauritius Renninger; Jean-Pierre Vigier; Luciano Fonda; Georg Süssmann; John S. Bell; Franco Selleri; Otto Robert Frisch; Mario Schönberg; International Centre for Theoretical Physics; University of São Paulo; Third World science; Cold War; foundations of quantum mechanics; measurement problem; negative-result measurements; philosophy of physics; politics; scientific controversy.

\section{Introduction}

Klaus Stefan Tausk (figure 1) was born in Graz, Austria, on April 11, 1927, and emigrated as a youth with his Jewish parents to São Paulo, Brazil, in 1938. He is virtually unknown among physicists and historians of physics today, although he was one of the protagonists in a controversy that helped to establish the field of the foundations of quantum mechanics: In 1966, while working as a doctoral student at the International Centre for Theoretical Physics (ICTP) in Trieste, Italy, he circulated a preprint, ${ }^{1}$ based upon some original arguments, in which he criticized a paper that Adriana Daneri,

* Osvaldo Pessoa, Jr., is Professor of Philosophy of Science at the University of São Paulo, Brazil; his reseach interests include the measurement problem in quantum mechanics. Olival Freire, Jr., teaches history of physics at the Federal University of Bahia, Brazil; his research interests include the history of the foundations of quantum mechanics. Alexis De Greiff teaches sociology at the National University of Colombia in Bogotá; his research interests include the discourses and practices of South-North scientific exchanges in the 20th century. 


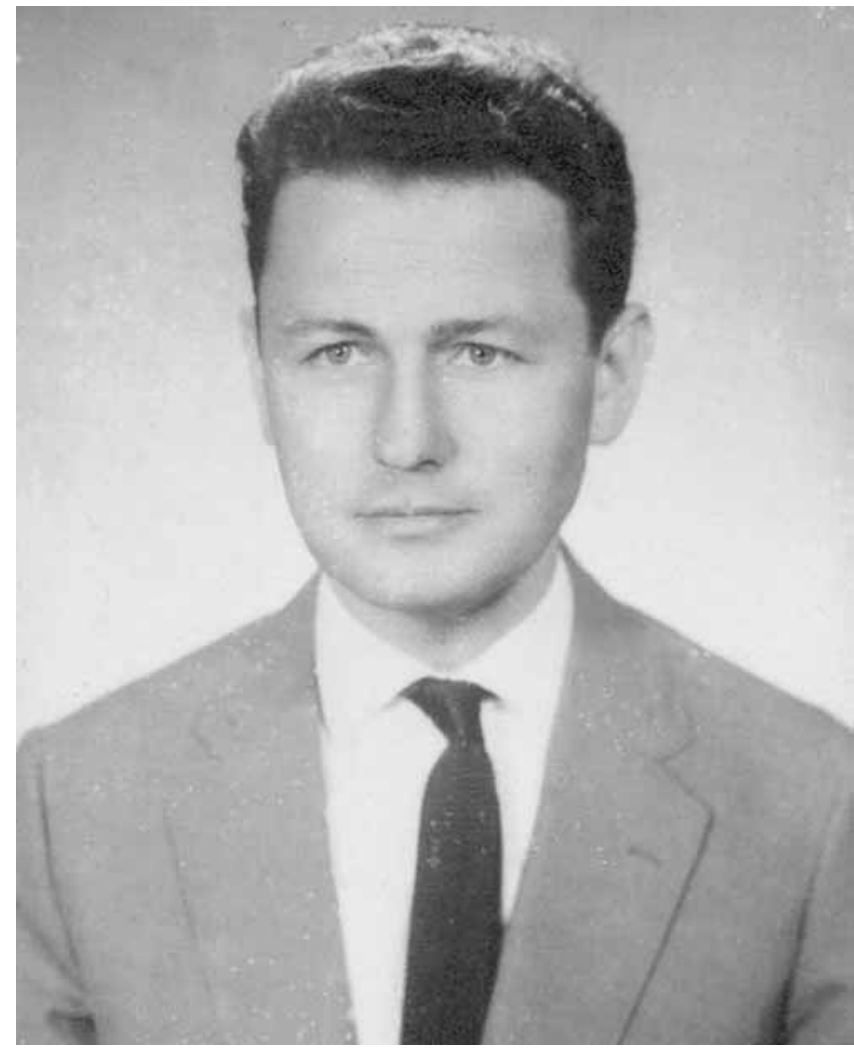

Fig. 1. Klaus Stefan Tausk (b. 1927). Credit: Courtesy of Klaus Tausk

Angelo Loinger, and Giovanni Maria Prosperi had published in $1962 .^{2}$ The ensuing heated controversy went well beyond strictly scientific issues, with a number of prominent theoretical physicists, including Léon Rosenfeld, David Bohm, Josef Maria Jauch, Eugene P. Wigner, and John S. Bell taking sides in it. Tausk's work was eventually neglected and ultimately forgotten, even by those who used it to advance their own interpretations of quantum mechanics.

Tausk's failure to be recognized for his achievement, in our view, can be attributed to his careless and aggressive style of writing and to his inadequate social skills in communicating his ideas. It also was conditioned by the circumstances surrounding the ongoing debate on the foundations of quantum mechanics, in particular, the lack of respect for this field in the eyes of most physicists at the time, and by the controversial reputation of the ICTP owing to its questionable publication policy.

The historian and philosopher of science Ernan McMullin has emphasized that scientific controversies involve much more than logical problems concerning hypotheses and evidence; they are social conflicts involving personality traits and other historical contingencies. ${ }^{3}$ The Tausk controversy took place within the context of particular sci- 
entific, historical, philosophical, and political circumstances: The foundations of quantum mechanics had become controversial among physicists for a number of reasons, including the issues raised by the Bohr-Einstein debate of 1935, by Soviet criticisms of Bohr's principle of complementarity in the 1950s, and especially by David Bohm's "causal interpretation" of quantum mechanics of $1952,{ }^{4}$ which offered a deterministic picture based upon "hidden variables," 5 an interpretation that was set within the political context of the Cold War. ${ }^{6}$ This impinged upon the Tausk controversy, as we shall see, but it also was affected by a different kind of politics, one that reflected attitudes of physicists working in scientific centers in developed countries toward those working in Third World countries, a tension that was mediated by the concrete institutional setting of the ICTP in Trieste, Italy.

\section{Scientific Background}

Tausk's preprint focused on the "measurement problem," one of the central problems in the foundations of quantum mechanics. ${ }^{7}$ Setting aside the more heterodox proposals such as Bohm's causal interpretation of 1952 and Hugh Everett's relative-state interpretation of $1957,{ }^{8}$ by the late 1950 s there were two orthodox points of view that divided theoretical physicists on the measurement problem.

On one side were physicists such as John von Neumann, Georg Süssmann, Josef Maria Jauch,* and Eugene P. Wigner, who described the measurement apparatus used in quantum-mechanical experiments in an exact way (that is, without approximations) as a quantum system. Sometimes called the "Princeton school," 9 they applied the Schrödinger equation (or another equivalent equation describing a unitary state evolution) to the composite system consisting of apparatus and quantum object, and concluded that such a description is insufficient to account for all aspects of the measurement process - a formal result that was an example of what became known as an "impossibility proof," which von Neumann first derived in $1932,{ }^{10}$ and which served to justify his "projection postulate" describing the discrete change of state as an indeterministic process that accompanies a measurement. The projection postulate thus was regarded as an independent principle, to be added to the five fundamental axioms (or six, if one considers indistinguishable particles) of nonrelativistic quantum mechanics. ${ }^{11}$ The impossibility proof, as reformulated by Wigner in $1963,{ }^{12}$ prohibited the reduction of the projection postulate to the other fundamental axioms.

On the other side of the postwar debate were physicists such as Niels Bohr, Pascual Jordan, Günther Ludwig, Paul Feyerabend, H.S. Green, Adriana Daneri, Angelo

* Jauch was born in Lucerne, Switzerland, on September 20,1914, received his Diplom at the Federal Institute of Technology (Eidgenössische Technische Hochschule) in Zurich in 1938, and his $\mathrm{Ph} . \mathrm{D}$. degree in theoretical physics at the University of Minnesota in 1939. He then returned to Zurich as an Assistant in theoretical physics (1940-1942), but then left again for the United States, where he was an Instructor and Assistant Professor of Physics at Princeton University (1942-1945), a research physicist at Bell Telephone Laboratories (1945-1946), and Associate and Full Professor of Physics at the University of Iowa (1946-1959) before returning to his home country permanently in 1960 as Professor of Physics at the University of Geneva. 
Loinger, Giovanni Maria Prosperi, and Léon Rosenfeld, who argued that the measurement process can be described adequately by a statistical mechanics of quantum processes, which would amount to a thermodynamic approach. These physicists were closely allied to the orthodox Copenhagen interpretation and its central concept of complementarity, ${ }^{13}$ but they proposed to modify it by introducing certain approximations in the limit of large numbers. Some, such as Jordan in $1949,{ }^{14}$ clearly pointed out the statistical hypothesis that was being used and proposed to simply substitute it for the projection postulate. Others, such as Daneri, Loinger, and Prosperi in 1962, argued that the approximations involved no fundamental physical principle, so the projection postulate could be eliminated and reduced to the other fundamental axioms. This clashed with the impossibility proof and stirred up the debate on the measurement problem, beginning with the papers that Feyerabend and Süssmann presented at the Colson Research Society Symposium at the University of Bristol, England, in $1957 .{ }^{15}$

The postwar thermodynamic approach arose as an "objectivist" alternative to the "idealistic" views that were widespread in the 1930s. Bohr clearly reflected this change when he stressed in 1958 that a measurement could be made in the absence of a conscious observer, "based on registrations obtained by means of suitable amplification devices with irreversible functioning...." 16 The idea was that a measurement is an objective thermodynamic process. The problem that was left open was how to describe mathematically, in the most satisfactory way, the irreversible amplification process that leads from a microscopic event to a macroscopic registration.

Daneri, Loinger, and Prosperi (hereafter DLP), who were working in the Milan section of the Italian Istituto Nazionale di Fisica Nucleare, published the most ambitious theory of the thermodynamic-amplification approach in 1962 in the journal Nuclear Physics edited by Léon Rosenfeld. ${ }^{17}$ They divided the measurement process into two stages. First, the microscopic quantum object interacts with the apparatus as prepared in a "metastable" state, which produces a nonequilibrium state. Second, amplification takes place, which involves certain restrictions known as "ergodicity conditions" and which, as defined by Léon van Hove, ${ }^{18}$ were weaker than those used earlier. They guaranteed that the system would return to equilibrium, according to the expected behavior of the measurement apparatus, in the limit of an infinite amount of time. Rosenfeld approved of DLP's theory, emphasizing the importance of the second, amplification stage. ${ }^{19}$

DLP's theory was the culmination of a series of investigations that Milanese and Pavian theoretical physicists, such as Loinger, Prosperi, Pietro Bocchieri, and Antonio Scotti, had undertaken since the end of the 1950s on the ergodic hypothesis and its applications in statistical mechanics and quantum mechanics. Specifically, their search for a more realist solution to the measurement problem, in opposition to von Neumann's, was inspired by the Italian theoretical physicist Piero Caldirola, who helped to popularize DLP's theory in 1965, which subsequently was widely cited in the literature. $^{20}$

The thermodynamic approach gradually declined in importance, however, for two main reasons. First, Wigner's arguments of $1963,{ }^{21}$ which as noted above were based upon the impossibility proof, undermined it. Second, Tausk's argument of $1966,{ }^{22}$ as well as Jauch, Wigner, and Mutsuo M. Yanase's of $1967,{ }^{23}$ which were based upon "negative-result measurements," as had been discussed by physicist Mauritius Renninger at 
the University of Marburg, Germany, in $1960,{ }^{24}$ also undermined it. Consider the following example. Imagine an experiment in which a quantum-mechanical object (we will call it a "particle" but will not require it to have a well-defined position) strikes with equal probability one of two detectors placed in paths $A$ and $B$. Now suppose that the detector in path $A$ is removed and the particle is sent to the apparatus. If after a certain time the observer sees no signal at the detector in path $B$ (assuming that the detectors are perfectly efficient), the observer then would conclude that the particle traveled along path $A$, which amounts to a state reduction or collapse. No amplification occurred, however, which clearly shows that amplification is not a necessary condition for state reduction or collapse (although in practice it might be a sufficient condition).

Although Tausk's 1966 argument, which was based upon such negative-result measurements, was seen by many as a knock-out argument against DLP's theory following Jauch, Wigner, and Yanase's paper of 1967, Loinger defended it in $1968,{ }^{25}$ showing that it did not require amplification. Their formalism required only that a coupling had to exist between quantum object and detector, a situation that Robert H. Dicke clarified much later, in $1981 .^{26}$

\section{Tausk in Trieste}

Tausk studied physics at the University of São Paulo, Brazil, from 1947 to 1951, and later worked there on cosmic-ray experiments with the Czech physicist Kurt Sitte* in 1953-1954. ${ }^{27} \mathrm{He}$ also became acquainted with David Bohm (figure 2), ** who worked there from October 1951 to January 1955, although Tausk later claimed that he was not influenced by Bohm's causal interpretation, because he did not have an adequate understanding of quantum mechanics at the time. ${ }^{28}$ Tausk then interrupted his studies for a few years, beginning graduate research in 1958, which included a year in Hamburg (1959-1960) to work with Harry Lehman on quantum-field theory. Tausk also met Georg Süssmann in Hamburg, who was on a visit from Frankfurt, and who was doing significant work on measurement theory in quantum mechanics. ${ }^{29}$

* Sitte was born in Reichenberg, Bohemia (Liberec, Czechoslovakia) on December 1,1910, and received his Ph.D. degree in physics at the German University of Prague in 1933. As a non-Jew but outspoken left-wing anti-Nazi, he was arrested in Prague immediately after the German invasion of Czechoslovakia in March 1939, was imprisoned in the Dachau and Buchenwald concentration camps, and was liberated in April 1945. After the war, he had appointments at the Universities of Edinburgh and Manchester (1946-1948) and at Syracuse University (1948-1953) before accepting a visiting professorship at the University of São Paulo, Brazil (1953-1954) and subsequently an appointment at the Technion in Haifa, Israel.

** Bohm was born in Wilkes-Barre, Pennsylvania, on December 20,1917, and received his Ph.D. degree in physics at the University of California at Berkeley in 1943, where he remained until 1947. He then was an Assistant Professor of Physics at Princeton University (1947-1951), but his contract was not renewed after he took the Fifth Amendment in testimony before the U.S. House Committee on Un-American Activities. He immigrated to Brazil, becoming Professor of Theoretical Physics at the University of São Paulo (1951-1954), after which he immigrated to Israel, where he worked at the Technion in Haifa (1955-1957), and then immigrated to England, where he was Professor of Theoretical Physics first at the University of Bristol (1957-1961) and subsequently at Birkbeck College, University of London. 


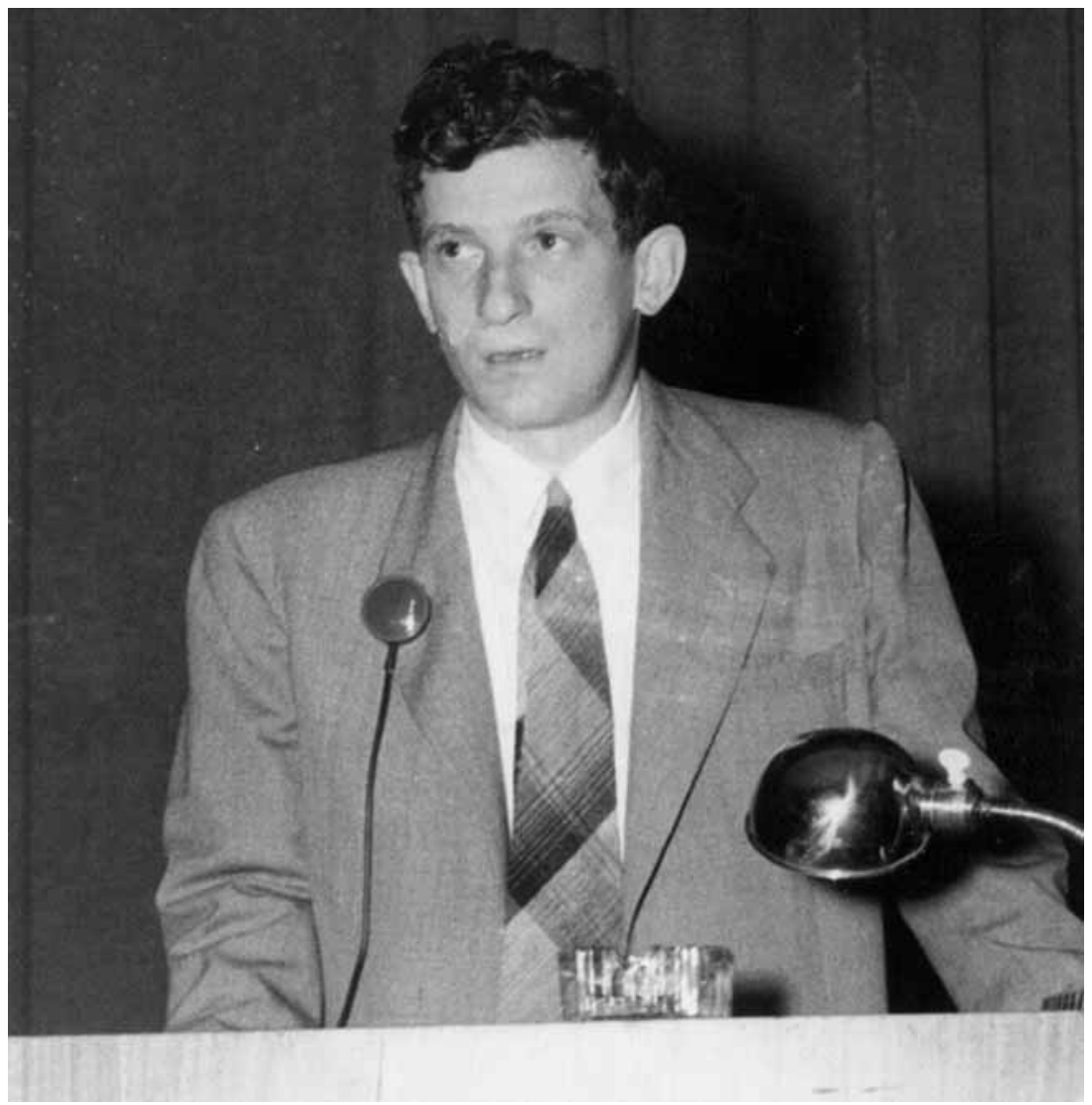

Fig. 2. David Bohm (1917-1992) in Rio de Janeiro in 1952. Credit: Museu de Astronomia e Ciências Afins (MAST).

Returning to São Paulo in 1962, Tausk read a paper of 1960 by Hitoshi Wakita on the measurement problem in quantum mechanics, ${ }^{30}$ which stimulated his interest in the subject, and he also came across Renninger's paper of 1960 on negative-result measurements. ${ }^{31}$ Renninger had used the thought experiment noted above to criticize the Copenhagen interpretation of quantum mechanics, denying that every measurement produces an uncontrollable disturbance on the observed object. Tausk too then began to question the Copenhagen interpretation and to work on the measurement problem.

In 1965 Tausk wrote to Abdus Salam (figure 3), Director of the International Centre for Theoretical Physics (ICTP), in Trieste, Italy, presenting himself as a doctoral student of the renowned Brazilian theoretical physicist Mario Schönberg, and received a scholarship to work at the ICTP. The ICTP had been created in June 1963 as a division of the International Atomic Energy Agency (IAEA) with the support of UNESCO.*

* United Nations Educational, Scientific, and Cultural Organization. 


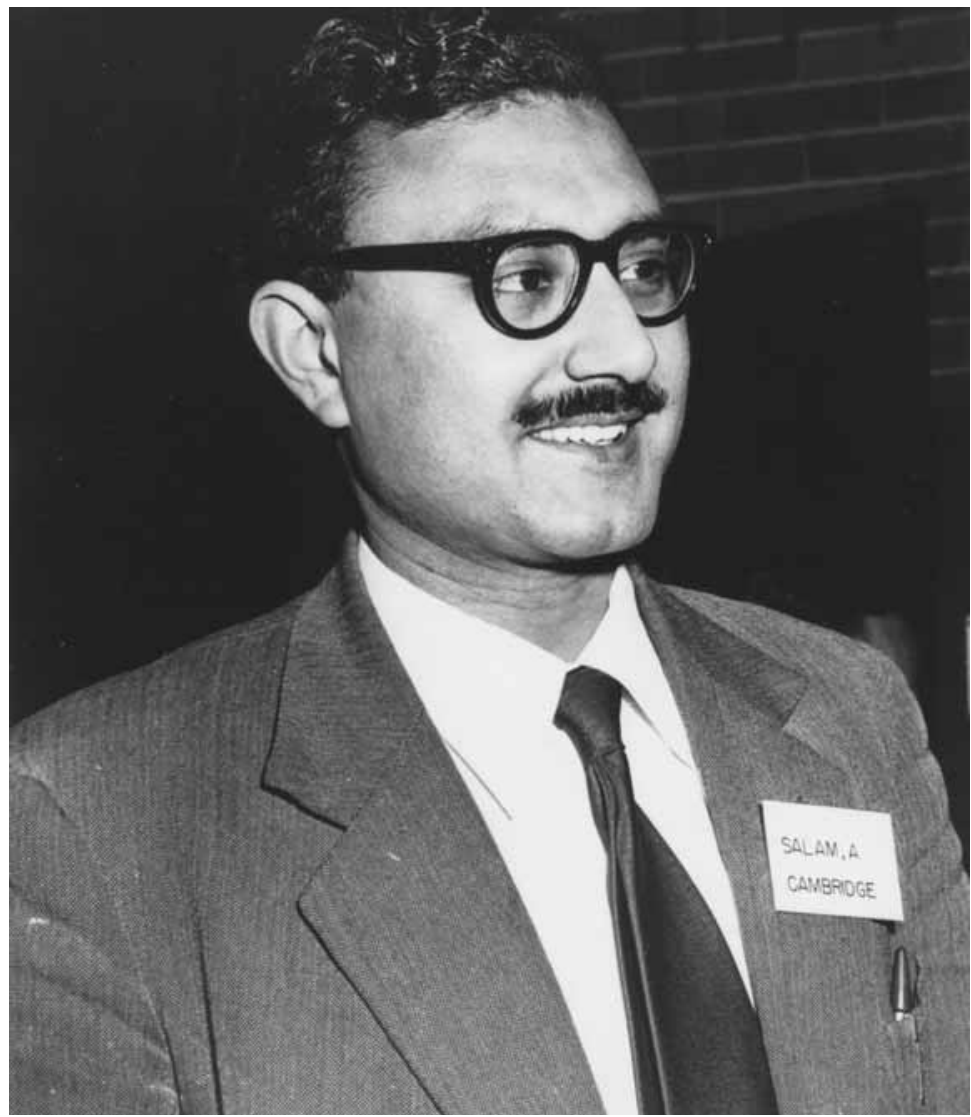

Fig. 3. Abdus Salam (1926-1996). Credit: American Institute of Physics Emilio Segrè Visual Archives, Marshak Collection.

It was in a delicate situation at the time, because it had been created over the opposition of India, the Soviet Union, the United States, and most of the developed countries. The Swedish physicist Sigvard Eklund, Director of the IAEA, was a friend of Rosenfeld, who during the negotiations to create the ICTP had proposed that it be located in Copenhagen, not Trieste. Rosenfeld and his Danish colleagues felt that the IAEA should support regional institutions such as NORDITA* in Copenhagen, because they were skeptical about supporting a center for theoretical physics in Trieste whose goal was to create a scientific elite in Third World countries. ${ }^{32}$

Tausk spent just over a year at the ICTP in Trieste, from the middle of 1965 until the end of September 1966. He had applied to the ICTP to carry out research on quantumfield theory, but he actually continued his studies on the measurement problem. Toward the end of his stay, he finished writing a paper entitled "Relation of Measure-

* Nordisk Institut for Teoretisk Fysik. 
ment with Ergodicity, Macroscopic Systems, Information and Conservation Laws," 33 in which he criticized the aforementioned paper by Daneri, Loinger, and Prosperi of $1962,{ }^{34}$ as well as the orthodox Copenhagen interpretation of quantum mechanics, especially the version of it that Werner Heisenberg had published in $1958 .{ }^{35} \mathrm{He}$ also criticized the preprint of a new paper by the Italian trio that circulated in February 1966. ${ }^{36}$ Tausk wrote his paper as a thesis to be submitted to the International Advanced School of Physics, a division of the ICTP under the directorship of Luciano Fonda. ${ }^{37}$ It began to circulate among physicists in August 1966.

As a scientist working at the ICTP, Tausk had the right to request that his paper be typed and fifty copies printed, without any refereeing, as an internal report of the ICTP. Contrary to the usual procedure, however, Tausk added an official ICTP cover to each copy of the report. He soon apologized to Rosenfeld for this breach in procedure, blaming it on his "ignorance of the regulations, a series of misunderstandings and to the absence of part of the staff from the Centre at the time...." 38

Tausk distributed his report as a preprint to a number of theoretical physicists, including Süssmann in Frankfurt, Germany; the Argentinian Daniele Amati, who had studied a few years in Rio de Janeiro and now worked in Trieste; the South African Jeffrey Bub, who had received his Ph.D. degree under Bohm at Birkbeck College, University of London, in 1966 and now was a Research Specialist at the University of Minnesota in Minneapolis; and the French Marxist Jean-Pierre Vigier in Paris, whom Tausk had met in São Paulo in 1954 while Vigier was working with Bohm there. Tausk encountered Vigier again in Trieste, who extended an offer to Tausk to work with him and Louis de Broglie on the measurement problem at the Institut Henri Poincaré in Paris.

Tausk also sent a copy of his preprint to Loinger, who was now at the University of Pavia, and one also came into the hands of Rosenfeld at NORDITA in Copenhagen. In 1965 Rosenfeld had written a paper explicitly defending DLP's theory, ${ }^{39}$ which Tausk also had criticized. Loinger and Rosenfeld now not only disagreed with Tausk's preprint, they were enraged by it.

Daneri, Loinger, and Prosperi (DLP) had considered their work to be "an indispensable completion and a natural crowning of the basic structure of present-day quantum mechanics," being "firmly convinced that further progresses in this field of research will consist essentially in refinements" of their approach. ${ }^{40}$ Note the rhetorical aspect of their immodest claims. Tausk, however, now declared that, contrary to DLP's claims, "no connection between ergodicity and reduction of state has been established," and he pointed to a class of measurements, Renninger's negative-result measurements, "for which ergodicity considerations are obviously irrelevant." ${ }^{41}$ Tausk bluntly concluded: "Recent claims by the same authors ... and L. Rosenfeld ..., which hold this attempt to be of fundamental importance, are thereby contradicted." We comment further on Tausk's arguments and style of writing in the Appendix.

\section{Loinger's and Rosenfeld's Attacks}

Loinger was the first to react to Tausk's preprint. On September 9, 1966, he wrote an open letter to Gilberto Bernardini, ${ }^{42}$ President of the Società Italiana di Fisica (SIF), 
requesting that it be published in the Bollettino della S.I.F. In it Loinger deplored the increasing number of worthless preprints that were being sent out from various institutions (implying especially the ICTP in Trieste), and were then being submitted for publication to Il Nuovo Cimento, the official journal of the SIF. To combat this pernicious practice, Loinger offered two suggestions: First, Il Nuovo Cimento should publish the title, author, and institution of all papers it rejected for publication, thus forcing irresponsible institutions to control the quantity of worthless papers they released for publication. Second, the SIF should institute an annual "antiprize" (antipremio) for the worst preprint written in Italy - and the preprint that should be selected for the first antiprize, lest it "escape," was Tausk's!

Loinger's attack thus was directed not only at Tausk's preprint, but also at the entire ICTP in Trieste. A couple of weeks later, on September 22, 1966, Loinger also sent an open letter to the widely circulated Italian magazine L'Europeo, ${ }^{43}$ questioning the financial support that the Italian government was providing to the ICTP, and criticizing the doubtful rigorousness of the papers emanating from it. His view here was a common one among European and American physicists. In fact, the absence of internal control over papers being written at the ICTP was intentional: Abdus Salam, its Director, wanted to maximize the publication opportunities of scientists from Third World countries. ${ }^{44}$

On September 20, 1966, Rosenfeld wrote a letter to Salam, ${ }^{45}$ calling Salam's attention to Tausk's preprint. Rosenfeld began by implicitly but clearly questioning the publication policy of the ICTP:

From the inexhaustible flow of preprints from your Institute I picked out the other day one with the somewhat bombastic title "Relation of Measurement with Ergodicity, Macroscopic Systems, Information and Conservation Laws" by a certain K.S. Tausk. ${ }^{46}$

That opening sentence, coming from a leading theoretical physicist who earlier had questioned locating the ICTP in Trieste, certainly appears to have been an attempt to intimidate Salam, who was constantly striving to demonstrate that the ICTP was worthy of support on the basis of its scientific merits. But Rosenfeld went much further, declaring that Tausk's preprint

is such incredible thrash [sic] that I hardly could believe my eyes when I read it. I feel that I ought to write you about it in the event that (as I hope) this masterpiece has just escaped your attention.... The author is, I suppose, very young and inexperienced; one good turn you could do him, since you presumably know him better than I do, would be to represent that before blandly assuming that the trivialities which fill his paper could have been overlooked by such people as Niels Bohr and Heisenberg, he might perhaps reflect that he could be the one who misses the point. ${ }^{47}$

Note again Rosenfeld's inference that there was a lack of control at the ICTP over the preprints that were being sent out under its banner.

Salam replied to Rosenfeld one week later, saying "I wish to tender to you my sincerest apologies for Mr. Tausk's paper which reached you." ${ }^{48} \mathrm{He}$ explained the ICTP's 
rules governing the distribution of preprints, and how Tausk had managed to put an ICTP cover on his internal report.

Mr. Tausk is a special pupil of Mario Schönberg in Brazil. I have not had a chance to see him yet. He is due to leave us at the end of this month to join the Vigier group in Paris. I would request you that you may consider this episode as part of the old battles and in no case an expression of opinion from the Centre here. ${ }^{49}$

These "old battles" were the earlier battles over the interpretation of quantum mechanics.

Rosenfeld was appeased, writing to Salam one week later:

Since, however, this is clearly a case of lack of foresight with no evil intent on his [Tausk's] part, I think one ought not be too severe with him and rather dismiss the whole matter without more ado. I am glad to know (for the centre's sake) that Tausk's paper will not receive more publicity from the centre, but I have no illusions about what the Vigier group is going to do with it. However, this is another story. ${ }^{50}$

Rosenfeld had succeeded in neutralizing Salam. Tausk no longer would be supported by the Director of the ICTP, the institution where he had written his preprint and from which he had circulated it. Thus began Tausk's isolation from the community of theoretical physicists.

\section{Bohm's, Jauch's, and Fonda's Defenses of Tausk}

Meanwhile, Luciano Fonda, Director of the International Advanced School of Physics, a division of the ICTP, had written to two experts on the foundations of quantum mechanics, David Bohm at Birkbeck College, University of London, and Josef Maria Jauch at the University of Geneva, asking them for their opinions of Tausk's preprint. Bohm responded in a short handwritten letter on September 26, 1966, also sending copies to Salam, Tausk, and Paolo Budini, Deputy Director of the ICTP, saying: "I have read Dr. Tausk's paper, and I feel that what he writes is correct. I myself would suggest that he should publish his paper as a short article." 51 A week later Bohm also wrote a three-page typed letter to Tausk, clarifying "the confusion between the individual and the ensemble, which is contained in the argument of DLP." 52 Given Bohm's heterodox position on the foundations of quantum mechanics, however, it is not clear whether his support was helpful or unhelpful to Tausk. In any case, his opinion perhaps did not carry much weight among most quantum theorists at the time.

Jauch (figure 4) responded to Fonda on October 4, 1966, declaring that a "criticism of the paper by Daneri et al. is certainly most useful," and agreeing with Tausk's conclusion that "no connection between ergodic properties of the measuring apparatus and the reduction of state has been established by DLP." 53 Jauch noted, however, that certain statements in Tausk's paper were unclear and a few arguments badly constructed, and he complained that Tausk had failed to cite earlier work, in particular Wigner's 1963 and Jauch's 1964 papers. ${ }^{54}$ "In conclusion, I should say that a paper in this form would not be permitted to leave my institute. In [sic] the other hand a criti- 


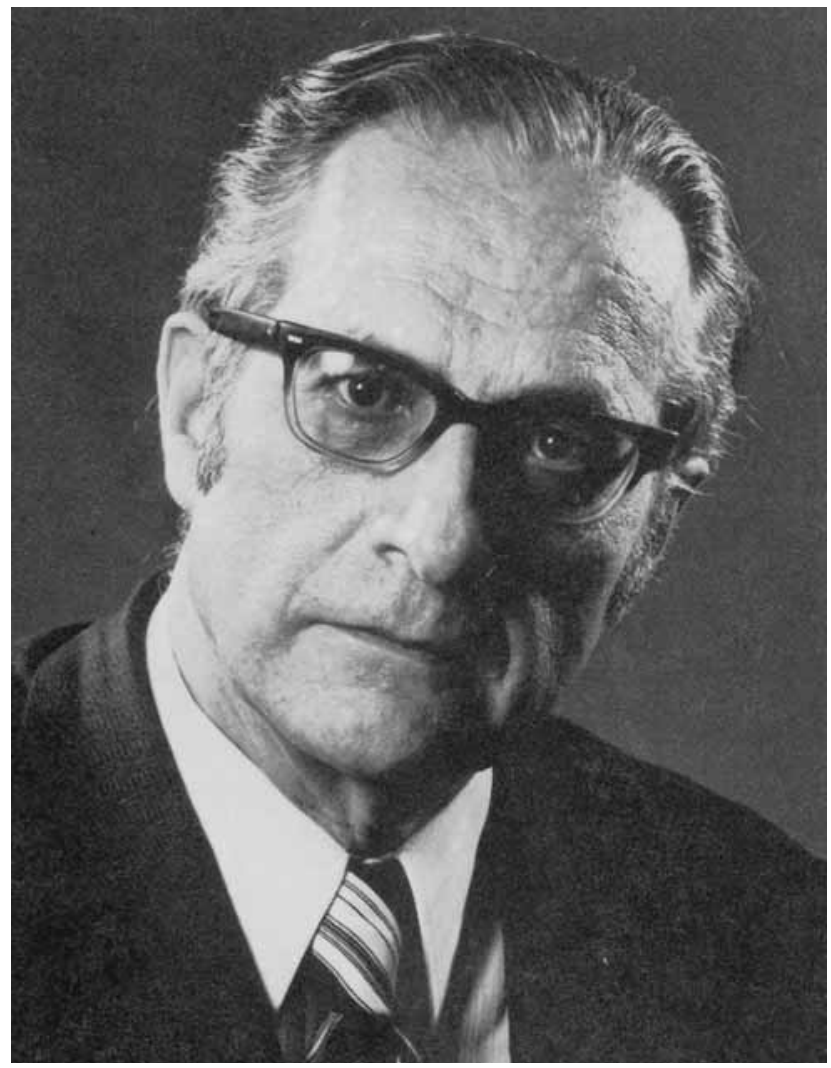

Fig. 4. Josef Maria Jauch (1914-1974) around 1965. Credit: Physics Library, University of Geneva.

cism of Daneri et al. is necessary and could be made in a more objective and dignified way on several grounds." 55

Meanwhile, Tausk had spoken to Salam, who showed him Rosenfeld's letter of October 4, 1966. Six days later, Tausk wrote directly to Rosenfeld, assuming responsibility for having broken the ICTP's publication rules, but then adding:

Fortunately for my reputation your opinion about my paper is not universal among those who have given serious thought to the problem of measurement: Prof. David Bohm thinks that what I wrote is correct, and he advised me to publish it. Prof. Louis de Broglie has sent me one of his books with the inscription "avec l'homage de l'auteur" in acknowledgment of this paper. A letter from Prof. G. Süssmann contains the following: "I have read your paper with great interest. What you have said about DLPI* and about Rosenfeld's commentary seems to me to be completely evident." 56

* The Roman numeral I in DLPI denotes Daneri, Loinger, and Prosperi's first paper of 1962 (ref. 2) in contrast to their second paper of 1966 (ref. 36). 
In view of Bohm's and Jauch's letters to Fonda, Daniele Amati, Paolo Budini, and Fonda wrote an open letter on behalf of the International Advanced School of Physics of the ICTP to the Società Italiana di Fisica (SIF), arguing that it would be a mistake for the SIF to establish an antiprize for the worst paper published in Il Nuovo Cimento because

it could easily be the cause or the effect of personal issues. For example, the work of Tausk, indicated by Loinger as worthy of the year's antiprize, contains a severe criticism of a paper by Loinger himself, coauthored by Daneri and Prosperi. ${ }^{57}$

They then summarized Bohm's and Jauch's opinions of Tausk's preprint, which prompted an immediate and angry response from Loinger in Pavia, who wrote to the President of the SIP on October 20 regarding their "stupefying open letter," and concluded that "if Bohm and Jauch have really declared, with respect to the aforementioned masterpiece, what Amati, Budini, and Fonda claim, then they lost an excellent opportunity to remain silent." 58

Three days earlier, on October 17, Fonda had written to Tausk:

I have received the answer from Jauch and I see that he agrees with you on your criticism to Loinger's paper. I have agreed with professor Budini that your paper will be supported by the Advanced School of Physics; however, in that case we want you to take into account the suggestions and criticism of professor Jauch to your manuscript. Once you have revised your manuscript, please send it to me and I will forward it to the journal you prefer. ${ }^{59}$

Tausk later claimed that he never received a copy of Jauch's letter of October 4 to Fonda. ${ }^{60} \mathrm{He}$ never revised his manuscript and did not return it to the International Advanced School of Physics to be forwarded for publication. He claimed that he did submit an article on his work to the American Journal of Physics, but that its editor had received negative reports from two referees and hence had declined to publish it.

\section{Further Developments}

Tausk did not know that Daniele Amati had sent his preprint to the Northern Irish theoretical physicist John Stewart Bell at CERN* in Geneva, and that Bell also had received reprints of Loinger's papers. Bell commented to Loinger on his and his colleagues' work in a letter of October 26, 1966:

It appears to me that ergodicity is relevant in showing the approximate absence of interference phenomena with macroscopically different states. But I think that nobody doubted this, and so am unable to attach fundamental importance to the formal discussion. This feature of large systems is for me about as relevant to the question of principle as is, for example, apparent macroscopic irreversibility to the question of reversibility of the fundamental Hamiltonian.... I am unable to accept all the

* Conseil Européen pour la Recherche de Nucléaire. 
details of Tausk as justified criticism of your paper. But I think his main points are right, and his general position sound. ${ }^{61}$

Loinger replied immediately and harshly: "Dear Prof. Bell, I think that you have not understood the essence of the problem of quantal measurement. Yours sincerely, A. Loinger." ${ }^{2}$ By this time, of course, owing to the groundbreaking paper that Bell had published two years earlier, ${ }^{63}$ he was becoming known as the most profound theoretical physicist working on the foundations of quantum physics.

In the meantime, Jeffrey Bub also had received a letter from Loinger criticizing some aspects of a paper that he and Bohm had published in $1966,{ }^{64}$ and in his reply to Loinger, Bub had reproduced a number of Tausk's ideas. Thus, when Bub acknowledged the receipt of Tausk's preprint on November 15, 1966, he told Tausk that it had "clarified several points which I had not understood properly before." ${ }^{65}$ In fact, Bub was the only person ever to cite Tausk's preprint in the literature - in an article of 1968 in which he criticized DLP's theory of measurement, declaring that, "Certain aspects of the following analysis have been influenced by a critical article on the D-L-P theory by K.S. Tausk...." 66

Jauch, Wigner, and Yanase thoroughly criticized DLP's theory in a paper they submitted for publication in late November $1966 .{ }^{67}$ They noted that DLP did not address the problem of negative-result measurements, but in this connection they did not mention Tausk, the first theoretical physicist to make this criticism. Jauch, as noted above, had become aware of Tausk's criticism when he reviewed Tausk's preprint, and had informed Wigner of it in a letter of September 16, 1966, saying:

I should perhaps mention that there has recently appeared an internal report from Trieste (ICTP internal Report 14/1966) written by K.S. Tausk which criticizes the paper by Daneri et al. rather severely. This paper contains some interesting points which should perhaps also be discussed in our paper. ${ }^{68}$

Wigner never mentioned Tausk's preprint in subsequent letters to Jauch. Further, Wigner wrote the first draft of their joint paper with Yanase, while Jauch made the final modifications to it. ${ }^{69}$ Jauch therefore should at least have introduced a citation to Tausk's preprint, which was known to him but not to Wigner and Yanase, but he did not do so. Franco Selleri at the University of Bari, Italy (to whom we shall return below) later commented caustically: "This is a further example (I had some myself) of how some well known physicists are eager of appropriating contributions coming from authors when they judge it safe to do so." 70

It may be that Jauch and Wigner, the two senior authors of their joint paper with Yanase, failed to cite Tausk's preprint because of his vaguely unfavorable image in the eyes of some European theoretical physicists, who pictured him as an unqualified Third World physicist, a polemist who criticized the orthodox interpretation of quantum mechanics without understanding it and, moreover, sympathized with the views of the French Marxist Vigier and his group in Paris. Perhaps Jauch and Wigner also did not want to align themselves and their work with criticisms that had been advanced in one of the numerous ICTP preprints, especially in one that had been written by a virtually unknown theoretical physicist. 


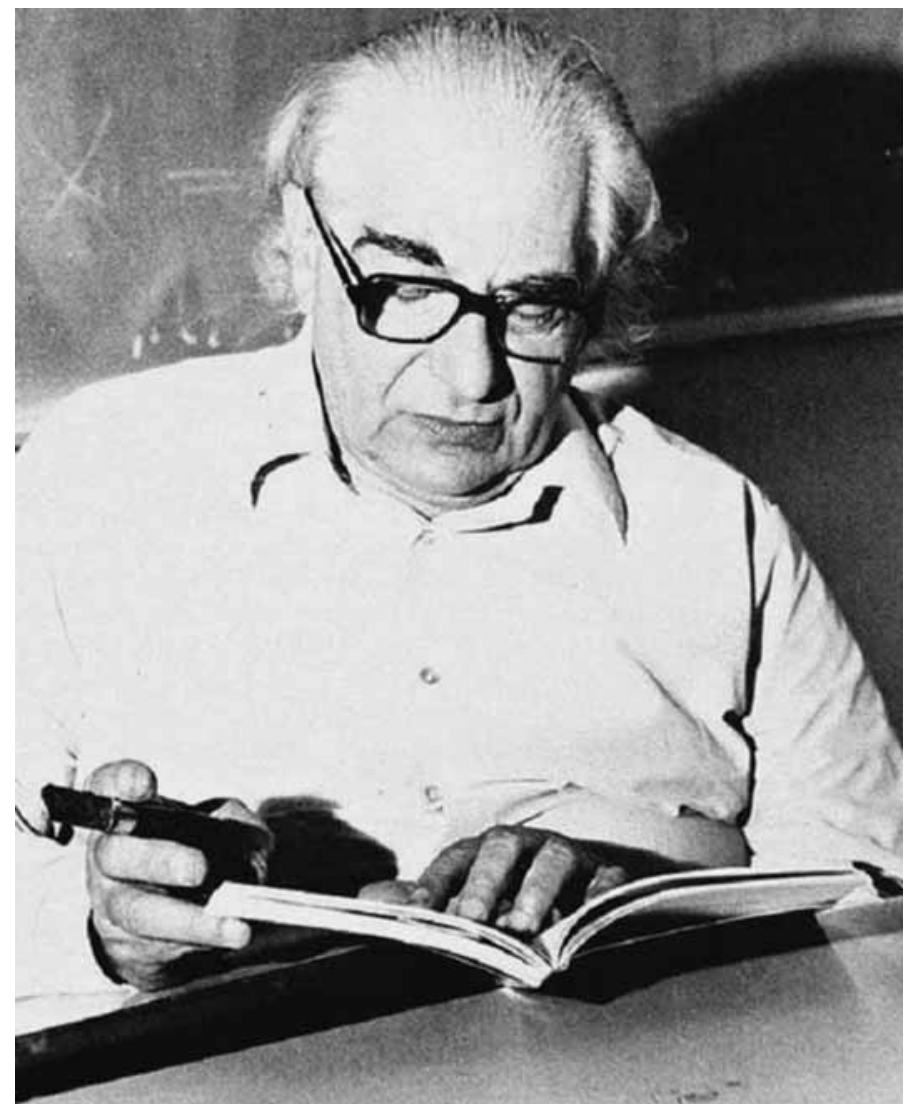

Fig. 5. Mario Schönberg (1914-1990) in 1982. Credit: Acervo Histórico do Instituto de Fisica da Universidade de São Paulo.

\section{Return to Brazil}

After leaving the ICTP in Trieste, Tausk spent some time in his hometown of Graz, Austria, and then returned to São Paulo, Brazil, to finish his Ph.D. thesis. His advisor, Mario Schönberg (figure 5), was extremely angry with him owing to the "scandal" he had precipitated in Europe. Schönberg and Rosenfeld were old friends; both were experts on cosmic-ray physics, and both were Marxists who were involved in international peace movements. Schönberg also was a close friend of the Milanese physicist Piero Caldirola, whom he had met in Rome in $1938 .{ }^{71}$ Schönberg evidently heard what his student Tausk had done at the ICTP from Rosenfeld, Salam, Caldirola, or someone else - and was greatly distressed and embarrassed by it.

Working alone, Tausk finished a draft of his thesis in 1967, writing it in Portuguese. In addition to the material in his controversial preprint, Tausk included a chapter in 
which he showed (possibly for the first time) that nonlocality in correlated systems cannot be used to transmit signals. Sometime later that year, in a first discussion of his work before an advisory committee (equivalent to a qualifying examination) whose members included Schönberg and the other Brazilian physicists Antônio Piza and Yogiro Hama, Schönberg severely criticized Tausk's work. The committee concluded that Tausk's thesis could not be defended as it was; Tausk would have to rewrite certain parts of it. ${ }^{72}$

Tausk did, and a few months later in 1967 defended his thesis, ${ }^{73}$ which turned out to be another traumatic experience for him. His advisor, Schönberg, refused to attend his defense because, according to Tausk, Schönberg would not talk to him. Tausk's thesisexamination board, which included the important Brazilian theoretical physicist Jorge Swieca at the University of São Paulo, who was highly critical of Tausk's work, almost flunked him. The only Brazilian physicist who read and approved of Tausk's work, according to Tausk, ${ }^{74}$ was the renowned experimental physicist Cesare Lattes at the new University of Campinas, who telephoned Tausk after his defense, asking Tausk to send him a copy of his thesis, which Lattes read overnight after he received it and then telephoned his approval of it. Lattes's favorable judgment, however, probably did not greatly influence the opinion of other Brazilian physicists.

Five years later, in 1972, Franco Selleri at the University of Bari, who was then deeply involved in examining the foundations of quantum theory, visited the University of São Paulo on the invitation of the theoretical physicist Henrique Fleming. While there, Selleri wrote a review of Tausk's thesis whose tone was similar to Bohm's and Jauch's: Selleri pointed out certain misunderstandings of Tausk, but overall he was sympathetic to Tausk's views. Thus, he noted that there were four weak points in Tausk's thesis but also eight original contributions in it, concluding that:

Tausk's thesis was very interesting reading and many physicists could no doubt benefit from it, once the philosophical ambiguities are cleared up. With more self-criticism Tausk probably will be able to contribute significantly to the understanding of the structure of the physical world. ${ }^{75}$

\section{Tausk's Preprint and the Rosenfeld-Wigner Dispute}

Loinger's and Rosenfeld's angry reactions to Tausk's preprint cannot be fully understood unless we consider the dispute on the measurement problem in which they were involved at the time. Thus, the thermodynamic-amplification program for solving the measurement problem, which had arisen in the 1950s and early 1960s, reached its most developed form in DLP's theory. Rosenfeld (figure 6) supported their theory, but a few other theoretical physicists criticized it, especially Wigner (figure 7), who followed von Neumann's approach, describing the measurement apparatus plus quantum object as a quantum-mechanical closed system, and suggesting that human consciousness plays an ineluctable role in the reduction of the wave packet. ${ }^{76}$

In response to Wigner's and other criticisms, Daneri, Loiner, and Prosperi published a second paper in 1966, raising the temperature of the controversy by declaring that Wigner, Abner Shimony, P.A. Moldauer, Yanase, Jauch, and others had not made "new 


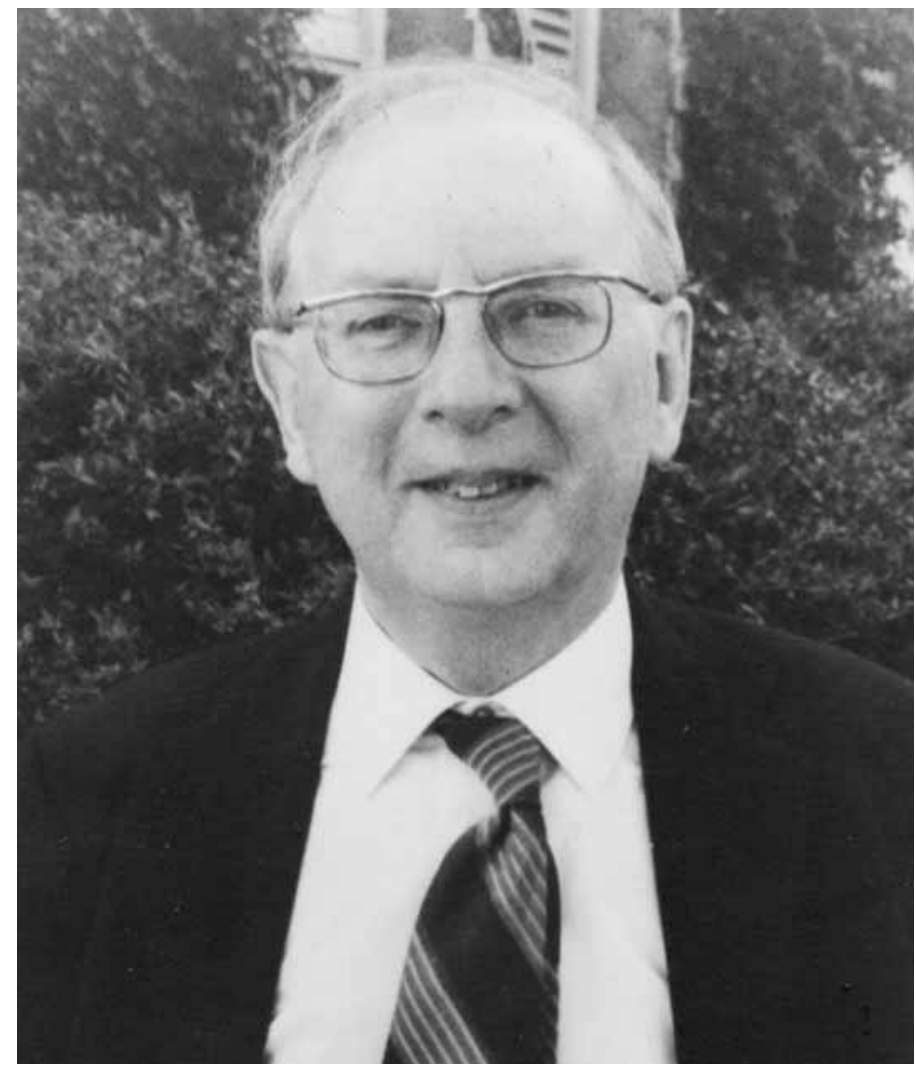

Fig. 6. Léon Rosenfeld (1904-1974). Credit: American Institute of Physics Emilio Segrè Visual Archives.

substantial contributions to the subject [the measurement problem]." 77 Their paper, which Tausk criticized in his preprint, also upset Wigner, who wrote to Jauch on September 6, 1966:

I just finished reading the article of Daneri Loinger and Prosperi in the July issue of Nuovo Cimento and am really a bit irritated by it. First of all, it is not good taste to say about a set of articles that they do not make substantial contributions to a subject. Needless to say, I am less concerned about myself than about other people who are much younger than I am and whose future careers such statements may hurt.... I am also saddened by Rosenfeld's endorsement of the article which, after all, considers it axiomatic that macroscopic systems have only states which can be described by classical mechanics. This is, of course, in conflict with quantum mechanics..... ${ }^{78}$

Wigner, in particular, was concerned that the future careers of Shimony and Yanase, his former doctoral students at Princeton University, might be damaged by DLP's attack. Three months later, on December 1,1966, Jauch, Wigner, and Yanase (now at Sophia 


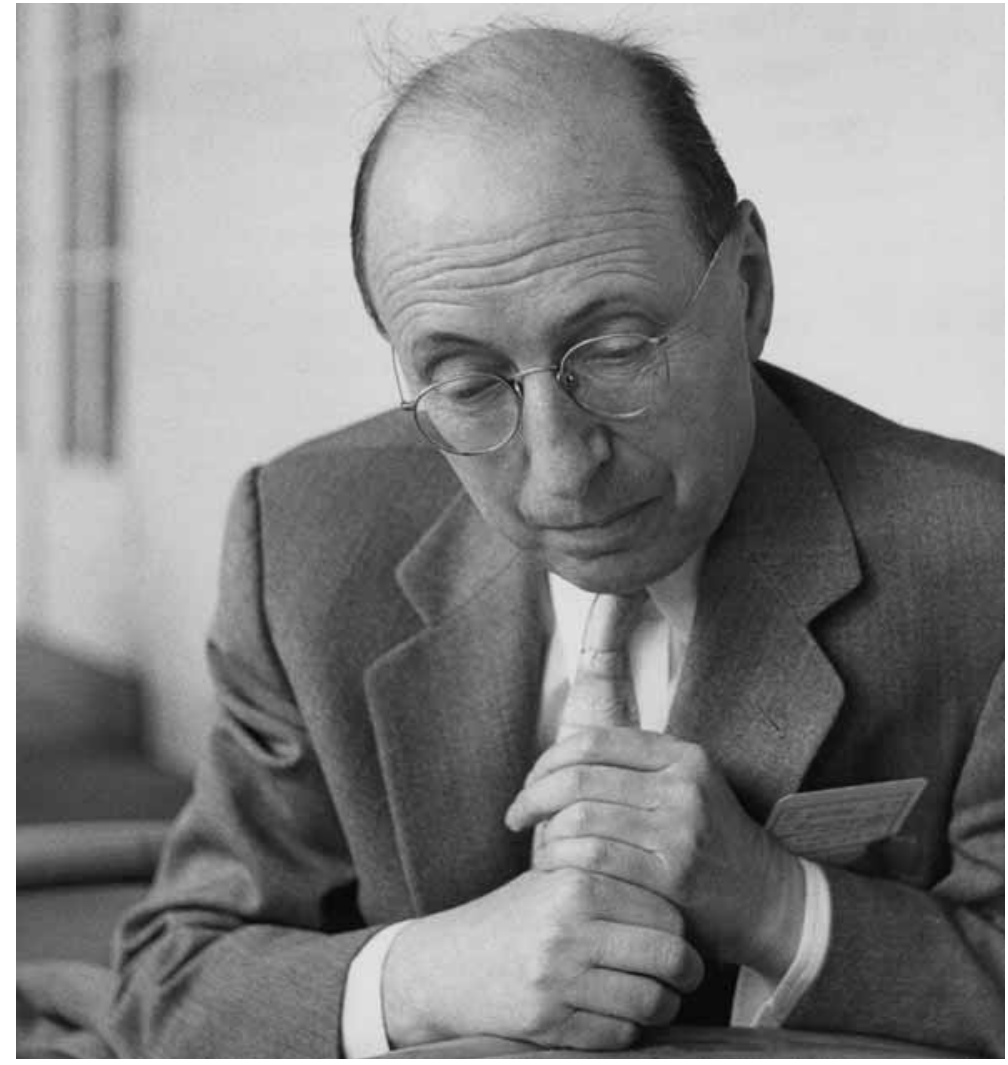

Fig. 7. Eugene P. Wigner (1902-1995). Credit: American Institute of Physics Emilio Segrè Visual Archives, Physics Today Collection.

University in Tokyo) submitted their detailed response to Il Nuovo Cimento for publication. ${ }^{79}$

The Austrian-English experimental physicist Otto Robert Frisch called attention to this dispute in his opening lecture at a meeting on the foundations of quantum theory in 1968:

I understand that at present there exists a controversy, roughly speaking between a group of people which includes Wigner as the best known person and another group centred on Milan in Italy [DLP], and that these two have different views on how this reduction [of the wave packet during a measurement] happens. ${ }^{80}$

The alignment of Wigner on one side of the dispute and of Rosenfeld on the other reflected their different intellectual heritages on the foundation and interpretation of quantum theory, with Wigner defending von Neumann's point of view and Rosenfeld Bohr's, Wigner stressing the axiomatization of quantum mechanics and Rosenfeld a more phenomenological approach. Their dispute, however, also reflected their diver- 
gent philosophical and political commitments, Wigner being a right-wing idealist who supported the American-Soviet arms race, and Rosenfeld being a left-wing Marxist who supported nuclear disarmament. ${ }^{81}$ This division among American and European quantum theorists was common at the time. That it affected the controversy precipitated by Tausk's preprint is clearly indicated in a letter that Frisch wrote to Hugo Tausk, who was both Frisch's cousin and Klaus's father, on September 16, 1967:

I have occupied myself a few times with Tausk's work, but I am not a theoretician and could not follow it. The questions which he addresses (essentially the question of the reality of the external world) seems to me very interesting. The orthodox Copenhagen interpretation says that physics does not deal with things but with measurements. That tastes like idealism, and is therefore rejected by the communists. Vice versa also applies, since anyone here in the West who doubts the orthodox interpretation - even for objective reasons - is suspect of communism. All this with the complexities and meaninglessness of a religious war, complete with converts: the greatest defender of the orthodoxy is a communist [Rosenfeld], and many in the opposition are fully bourgeoise.... 82

Klaus Tausk became embroiled in this dispute, perhaps without being fully aware of it, when he distributed his preprint in August 1966, thus aligning himself with Wigner and Jauch, the most prominent critics of Rosenfeld and of Daneri, Loinger, and Prosperi. At the same time, the Wigner-Rosenfeld dispute actually seems to have contributed to the acceptance of work on the foundations of quantum mechanics as a legitimate field of research. ${ }^{83}$ Ironically, Tausk thus helped to legitimize a field of research in physics in which he himself could no longer participate actively as a protagonist.

\section{Conclusions}

Tausk's promising research career on the foundations of quantum mechanics was cut short. He had made a bad name for himself in this field in Europe, and its study was considered to be unimportant in Brazil. In fact, this field gained general respect in Europe and America and other developed countries only in the 1970s. ${ }^{84}$ Tausk received no support from his thesis advisor Schönberg, and consequently was unable to revise his 1966 preprint and 1967 thesis for publication. His somewhat aggressive, arrogant, or in Jauch's words not very "dignified" style of writing contributed to his negative image, suggesting that psychological factors can be significant in the acceptance of scientific concepts.

Tausk applied for and was granted a second scholarship from the Brazilian Conselho Nacional de Pesquisa (CNPq) to work with Jean-Pierre Vigier in Paris in $1968,{ }^{85}$ but he was unable to do much work owing to the strikes and political turmoil there at the time. Returning to Brazil, he pursued an unimpressive career at the University of São Paulo, concentrating on his classes (he created a course on Groups and Tensors) and publishing very little. He became something of a folkloric figure in the Physics Institute, but did not gain much sympathy owing to his difficult personality. Further, in defense of his work, he could present only a few letters from individuals and the book that Louis de Broglie had inscribed to him. These documents, some of which were writ- 
ten by theoretical physicists like David Bohm who themselves were considered to be heterodox, were insufficient to gain support for the work of a young and unknown physicist. Tausk's tragedy was not that he got involved in a significant controversy on the interpretation of quantum mechanics, but that his work was forgotten.

Tausk thus was a kind of antihero in modern physics. He had original insights that were incorporated into the emerging field of the foundations of physics, since his 1966 preprint was read by physicists who came to play significant roles in this field. But he came from a Third World country, entered physics relatively late in life, chose a field of research of low scientific prestige at the time, made a few errors in his preprint, alienated his thesis advisor, was unable to publish his work in refereed journals, and had a difficult personality. Physicists have to learn how to write papers in an appropriate format, language, and degree of physical and mathematical detail to be accepted by others working in the field. Tausk lacked this ability. Salam, Director of the ICTP in Trieste, and Tausk's thesis advisor Schönberg, aligned themselves with Rosenfeld, turning Tausk into a scientific orphan. Attacking well-known scientists can lead to professional suicide.

A vital part of a physicist's training involves the development of social skills necessary to succeed in advancing his or her arguments and career. These include taking gossip into account, ${ }^{86}$ adopting an appropriate tone in a controversy, recognizing the right moment in which to intervene, and, most importantly, judicially choosing allies and rebuffing enemies. Tausk's career thus reveals a great deal about how competing scientists and their research programs interact, how philosophical and political commitments influence their scientific views, and how severe the difficulties are for someone doing science at the scientific periphery.

The Tausk controversy also reveals much about the kind of tacit knowledge scientists learn during their education and training. Young scientists can be wasted if they are not taught how to conduct themselves in scientific controversies, which is an art that goes well beyond reason and logic. The Tausk controversy exposes the risks and consequences of trying to participate in a scientific controversy in the absence of proper training and guidance. One value of the history of science is that it can be useful in showing young scientists the extent to which science is a social practice.

Salam's remark about the controversy that Tausk had precipitated, that one should "consider this episode as part of the old battles," 87 displays this social dimension and suggests an analogy between scientific controversies and military warfare. Both have winners and losers, but one may lose a battle while winning the war. In the debates over the interpretation of quantum mechanics, some like Niels Bohr won battles and some like David Bohm lost battles, but Bohm persevered in his hidden-variables program and in the end won some battles, or at least left his mark on the battlefield. There also, however, are those who lose a battle and then surrender. That seems to have been what Tausk did. 


\section{Appendix: Summary of Tausk's Arguments}

Tausk's arguments against Daneri, Loinger, and Prosperi's (DLP's) theory may be summarized as follows:

DLP's theory deals only with the statistical case. Tausk presents the reduction or projection postulate for an individual, "pure" case, and contrasts it with a statistical version, which he calls the "weak reduction postulate." He then argues that what DLP derive in their paper is not the projection postulate in the pure case, but in the statistical case. ${ }^{88}$ If so, then the "measurement problem" is not solved, and DLP's theory fails. Bohm accepted this argument in his letter to Tausk of October 1, 1966, ${ }^{89}$ and Bub developed it in his paper of $1968 .{ }^{90}$

DLP's analysis is circular. Tausk argues that DLP's description of measurement as occurring in two stages is circular. His argument, however, seems to follow from an incorrect reading of DLP's theory, which Jauch said was one of the "many details with which I disagree." 91

The ergodic hypothesis plays no role in DLP's theory. Tausk suggests that the use of the ergodic hypothesis in DLP's theory plays only a "purely psychological role," 92 a view that is based upon some sort of misunderstanding.

Negative-result measurements refute DLP's theory. This argument, which we have examined above, is correct in that it shows that amplification is not necessary for state reduction. However, as we noted, contrary to what one might expect, the existence of negative-result measurements does not refute DLP's theory, which, as Loinger argued, does not explicitly mention amplification. ${ }^{93}$ In any case, after Tausk presents his argument, he gives an example of his not very elegant style of writing that contributed to the negative reception of his preprint, declaring that: "To our mind, this argument shows that all attempts to fulfil [sic] the program of DLPI belong to the realm of wishful thinking or, occasionally, of just wishing." 94

Tausk made three additional points in his 1966 preprint and in his 1967 doctoral thesis, as follows:

The conservation of angular momentum paradox. In section 5 of his preprint and in his thesis, ${ }^{95}$ Tausk raises an apparent paradox concerning the angular momentum of an atom that passes through a Stern-Gerlach apparatus. Assuming that before detection the component of its angular momentum along the line joining the two magnets is zero, immediately after detection it is nonzero, either "up" or "down," depending upon which of the two detectors is triggered. Tausk asks how this apparent violation of conservation of angular momentum can be explained. A few years later, however, he realized that it could be explained by assuming that angular momentum is transferred to the Stern-Gerlach magnets. ${ }^{96}$

Critique of Heisenberg's epistemic conception of reduction. In his book, Physics and Philosophy of $1958,{ }^{97}$ Heisenberg claimed that state reduction expresses nothing more than an increase of our knowledge of a quantum-mechanical system. Tausk criticizes this view and suggests that quantum mechanics requires a completely new foundation. $^{98}$

No-signaling theorem. In his doctoral thesis, Tausk proved that an ensemble of two correlated particles, I and II, prepared in the same composite state, can never be used 
to transmit information at a speed greater than the speed of light. ${ }^{99}$ This probably is the first time that a physicist proved this rather simple result, which is known in the literature as a no-signaling theorem and is attributed to Philippe Eberhard. ${ }^{100}$

Finally, it is curious that Tausk continues by analyzing the famous Einstein-Podolsky-Rosen paper of $1935,{ }^{101}$ stating that they do not make use of the reduction postulate. That is incorrect: they do make explicit use of it. This illustrates both some of the shortcomings of Tausk's work and, because this error remained in his thesis even after he defended it, shows that the Brazilian community of physicists was still not well prepared to understand and discuss such philosophical subtleties as we have noted above on the foundations of quantum mechanics.

\section{Acknowledgments}

We thank Amélia Império Hamburger, Ana Maria Ribeiro de Andrade, Antônio Toledo Piza, David Kaiser, Ernst Hamburger (who translated the German letters and texts for us), Henrique Fleming, Joan Bromberg, John L. Heilbron, José Jeremias Oliveira, Olga Restrepo, and Yogiro Hama for their comments on a draft of our paper and, especially, Klaus Tausk for his collaboration on it. We thank the staffs in charge of the Eugene P. Wigner Papers, Manuscripts Division, Department of Rare Books and Special Collections, Princeton University Library, and of the Léon Rosenfeld Papers, Niels Bohr Archive, Copenhagen, for facilitating our research and granting permission to quote from their archival collections. We thank Jan Lacki for sending us the picture of Josef Maria Jauch. Osvaldo Pessoa, Jr., acknowledges support from the Fundação de Amparo à Pesquisa do Estado de São Paulo, process 01/07650-3; Olival Freire, Jr., thanks the Conselho Nacional de Pesquisa for grant 303967/2002-1 in support of this research; and Alexis De Greiff thanks the Dirección Nacional de Investigaciones of the Universidad Nacional de Colombia in Bogotá for its financial support of this research. Finally, we thank Roger H. Stuewer for his careful and thoughtful editorial work on our paper.

\section{References}

1 Klaus S. Tausk, "Relation of Measurement with Ergodicity, Macroscopic Systems, Information and Conservation Laws," ICTP Internal Report 14 (1966), 34 pp.

2 A. Daneri, A. Loinger, and G.M. Prosperi, "Quantum Theory of Measurement and Ergodicity Conditions," Nuclear Physics 33 (1962), 297-319; reprinted in John Archibald Wheeler and Wojciech Hubert Zurek, ed., Quantum Theory and Measurement (Princeton: Princeton University Press, 1983), pp. 657-679.

3 Ernan McMullin, "Scientific controversy and its termination," in H. Tristram Engelhardt, Jr. and Arthur L. Caplan, ed., Scientific controversies: Case studies in the resolution and closure of disputes in science and technology (Cambridge: Cambridge University Press, 1987), pp. 49-91, especially pp. 51-54, 59-61. See also “Controversies," Science in Context 11(2) (1998), 147-325, and Harry Collins and Trevor Pinch, The Golem: What everyone should know about science (Cambridge: Cambridge University Press, 1993).

4 David Bohm, “A Suggested Interpretation of the Quantum Theory in Terms of 'Hidden' Variables. I.” Physical Review 85 (1952), 166-179; idem, "II," ibid., 180-193; reprinted in Wheeler and Zurek, Quantum Theory and Measurement (ref. 2), pp. 369-396. 
5 James T. Cushing, Quantum Mechanics: Historical Contingency and the Copenhagen Hegemony (Chicago: University of Chicago Press, 1994), pp. 42-75.

6 Shawn Mullet, "Political Science: The Red Scare as the Hidden Variable in the Bohmian Interpretation of Quantum Theory," Senior Thesis HIS679, University of Texas at Austin, 1999; Russell Olwell, "Physical Isolation and Marginalization in Physics: David Bohm's Cold War Exile," Isis 90 (1999), 738-756; Olival Freire, Jr., "Science and exile: David Bohm, the cold war, and a new interpretation of quantum mechanics," Historical Studies in the Physical and Biological Sciences 36 (2005), 1-34.

7 Max Jammer, The Philosophy of Quantum Mechanics: The Interpretations of Quantum Mechanics in Historical Perspective (New York: Wiley, 1974), pp. 470-521; Bernard d'Espagnat, Conceptual Foundations of Quantum Mechanics, 2nd ed. (Reading, Mass.: W.A. Benjamin, 1976), pp. 159-229.

8 Bohm, "Suggested Interpretation" (ref. 4); Hugh Everett, III, "'Relative State' Formulation of Quantum Mechanics," Reviews of Modern Physics 29 (1957), 454-462; reprinted in Wheeler and Zurek, Quantum Theory and Measurement (ref. 2), pp. 315-323.

9 L.E. Ballentine, "The Statistical Interpretation of Quantum Mechanics," Rev. Mod. Phys. 42 (1970), 358-381, on 360, n. 2.

10 Johann v. Neumann, Mathematische Grundlagen der Quantenmechanik (Berlin: Julius Springer, 1932), pp. 157-173.

11 d'Espagnat, Conceptual Foundations of Quantum Mechanics (ref. 7), pp. 14-29.

12 Eugene P. Wigner, "The Problem of Measurement," American Journal of Physics 31 (1963), 6-15; reprinted in Wheeler and Zurek, Quantum Theory and Measurement (ref. 2), pp. 324-341.

13 Jammer, Philosophy of Quantum Mechanics (ref. 7), pp. 86-107, 197-211.

14 P. Jordan, "On the Process of Measurement in Quantum Mechanics," Philosophy of Science 16 (1949), 269-278.

15 P.K. Feyerabend, "On the quantum-theory of measurement," and G. Süssmann, "An analysis of measurement," in S. Körner, ed., Observation and Interpretation: A Symposium of Philosophers and Physicists (New York: Academic Press and London: Butterworths Scientific Publications, 1957), pp. 121-130, 131-136.

16 Niels Bohr, "Unity of Knowledge," in Niels Bohr, Atomic Physics and Human Knowledge (New York: Wiley, 1958), pp. 67-82, quote on p. 73.

17 Daneri, Loinger, and Prosperi, "Quantum Theory of Measurement" (ref. 2).

18 Léon van Hove, "The Ergodic Behavior of Quantum Many-Body Systems," Physica 25 (1959), 268-276.

19 Léon Rosenfeld, “The Measuring Process in Quantum Mechanics," Progress of Theoretical Physics, Supplement, Extra Number (1965), 222-231, especially pp. 225, 230; reprinted in Robert S. Cohen and John J. Stachel, ed., Selected Papers of Léon Rosenfeld (Dordrecht, Boston, London: D. Reidel, 1979), pp. 536-546, especially pp. 539-540, 545.

20 P. Caldirola, "Teoria della misurazione e teoremi ergodici nella meccanica quantistica," Giornale di Física 6 (1965), 228-237; Augusto Garuccio and Matteo Leone, "La fisica teorica tra Milano e Pavia (1945-1965)," in Giuseppe Giuliani, ed., Per una storia della Fisica Italiana 1945-1965. I. Física della matéria, fisica teorica, insegnamento della Fisica (Pavia: La Goliardica Pavese, 2002), pp. 35-80, especially pp. 66-68, 78-90. By June 2003, DLP's paper was cited more than 140 times in the literature; see the ISI Web of Science.

21 Wigner, "Problem of Measurement" (ref. 12).

22 Tausk, "Relation of Measurement with Ergodicity" (ref. 1).

23 J.M. Jauch, E.P. Wigner, and M.M. Yanase, "Some Comments concerning Measurements in Quantum Mechanics," Il Nuovo Cimento B 48 (1967), 144-151, especially 150-151 [received December 1,1966].

24 M. Renninger, "Messungen ohne Störung des Messobjekts," Zeitschrift für Physik 158 (1960), 417-421.

25 A. Loinger, "Comments on a Recent Paper Concerning the Quantum Theory of Measurement," Nuc. Phys. A 108 (1968), 245-249.

26 R.H. Dicke, "Interaction-free quantum measurements: A paradox?" Amer. J. Phys. 49 (1981), 925-930. 
27 Ana Maria Ribeiro de Andrade, "Os raios cósmicos entre a ciência e as relações internacionais," in Marcos Chor Maio, ed., Ciência, Política e relações internacionais ensaios sobre Paulo Carneiro (Rio de Janeiro: Editora Fiocruz, 2004), pp. 215-242.

28 Osvaldo Pessoa. Jr., interviews of Klaus S. Tausk, 1991 and 1999.

29 Georg Süssmann, "Über den Meßvorgang," Bayerische Akademie der Wissenschaften, Mathematisch-Naturwissenschaftliche Klasse, Abhandlungen, Neue Folge, 88 (1958), 3-41.

30 Hitoshi Wakita, "Measurement in Quantum Mechanics," Prog. Theor. Phys. 23 (1960), 32-40.

31 Renninger, "Messungen" (ref. 24); for a discussion, see Jammer, Philosophy of Quantum Mechanics (ref. 7), pp. 495-496.

32 Alexis De Greiff, "The tale of two peripheries: The creation of the International Centre for Theoretical Physics in Trieste," Hist. Stud. Phys. and Bio. Sci. 33 (2002), 33-59.

33 Tausk, "Relation of Measurement with Ergodicity" (ref. 1).

34 Daneri, Loinger and Prosperi, "Quantum Theory of Measurement" (ref. 2).

35 Werner Heisenberg, Physics and Philosophy: The Revolution in Modern Science (New York: Harper \& Brothers, 1958), pp. 44-58.

36 A. Daneri, A. Loinger, and G.M. Prosperi, "Further Remarks on the Relations Between Statistical Mechanics and Quantum Theory of Measurement," N. Cim. B 44 (1966), 119-128.

37 On Tausk's research proposal, see Luciano Fonda, "Report [to Salam] on the Fellows of the Centre," February 10, 1967, D.1713, International Advanced School of Physics, ICTP, Trieste.

38 Klaus S. Tausk in English to Rosenfeld, Graz, October 10,1966, Léon Rosenfeld Papers, Niels Bohr Archive, Copenhagen, Denmark.

39 Rosenfeld, "Measuring Process" (ref. 19).

40 Daneri, Loinger and Prosperi, "Further Remarks" (ref. 36), p. 127.

41 Tausk, "Relation of Measurement with Ergodicity" (ref. 1), abstract.

42 Angelo Loinger in Italian to President of the Società Italiana di Fisica, Pavia, September 9, 1966, Personal Archive of Klaus S. Tausk, São Paulo, Brazil.

43 A. Loinger, "Scienza e quattrini," L'Europeo 39 (September 22, 1966), 3.

44 Alexis De Greiff, "The International Centre for Theoretical Physics, 1960-1979: Ideology and Practice in a United Nations Institution for Scientific Cooperation and Third World Development," Ph.D. Dissertation, Imperial College of Science, Technology and Medicine, London, 2001, chapter 6.

45 Rosenfeld in English to Salam, Copenhagen, September 20, 1966, Personal Archive of Tausk (ref. 42).

46 Ibid.

47 Ibid.

48 Salam in English to Rosenfeld, Trieste, September 26, 1966, Rosenfeld Papers (ref. 38).

49 Ibid.

50 Rosenfeld in English to Salam, Copenhagen, October 4, 1966, Rosenfeld Papers (ref. 38).

51 Bohm in English to Fonda, with copies to Salam, Budini, and Tausk, London, September 26, 1966, Personal Archive of Tausk (ref. 42).

52 Bohm in English to K. Tausk, London, October 1, 1966, Personal Archive of Tausk (ref. 42).

53 Jauch in English to Fonda, Geneva, October 4, 1966, Rosenfeld Papers (ref. 38); the conclusion Jauch quoted was from Tausk, "Relation of Measurement with Ergodicity" (ref. 1), p. 22.

54 These missing citations were: Wigner, "Problem of Measurement" (ref. 12) and J.M. Jauch, "The Problem of Measurement in Quantum Mechanics," Helvetica Physica Acta 37 (1964), 293-316.

55 Jauch to Fonda, October 4, 1966 (ref. 53).

56 Tausk to Rosenfeld, October 10, 1966 (ref. 38). Tausk is quoting Georg Süssmann in German to Tausk, Frankfurt, September 16, 1966, Personal Archive of Tausk (ref. 42). Süssmann's original German is: "Ihre Arbeit habe ich mit grossem Interesse gelesen. Was Sie zu DPLI und zu Rosenfelds Kommentar sagen, leuchtet mir durchaus ein."

57 Daniele Amati, Paolo Budini, and Luciano Fonda in Italian to President of the Società Italiana di Fisica, Trieste, October 11, 1966, Rosenfeld Papers (ref. 38)

58 Angelo Loinger in Italian to President of the Società Italiana di Fisica, Pavia, October 20, 1966, Rosenfeld Papers (ref. 38). 
59 Fonda in English to Tausk, Trieste, October 17, 1966, Personal Archive of Tausk (ref. 42).

60 Pessoa interviews of Tausk (ref. 28), and Jauch to Fonda, October 4, 1966 (ref. 53).

61 Bell in English to Loinger, Geneva, October 26, 1966, Rosenfeld Papers (ref. 38).

62 Loinger in English to Bell, Pavia, October 31, 1966, Rosenfeld Papers (ref. 38).

63 J.S. Bell, "On the Einstein Podolsky Rosen Paradox," Physics 1 (1964), 195-200; reprinted in J.S. Bell, Speakable and Unspeakable in Quantum Mechanics, Revised ed. (Cambridge: Cambridge University Press, 2004), pp. 14-21, and in Wheeler and Zurek, Quantum Theory and Measurement (ref. 2), pp. 403-408.

64 D. Bohm and J. Bub, "A Proposed Solution of the Measurement Problem in Quantum Mechanics by a Hidden Variable Theory," Rev. Mod. Phys. 38 (1966), 453-469.

65 Bub in English to Tausk, Minneapolis, November 15, 1966, Personal Archive of Tausk (ref. 42).

66 J. Bub, "The Daneri-Loinger-Prosperi Quantum Theory of Measurement," N. Cim. B 57 (1968), 503-520, on 505, n. 10.

67 Jauch, Wigner and Yanase, "Some Comments" (ref. 23).

68 Jauch in English to Wigner, September 16, 1966, Eugene P. Wigner Papers, Manuscripts Division, Department of Rare Books and Special Collections, Princeton University Library, Box 71, Folder 3 .

69 Wigner in English to Jauch, September 6, October 5, October 25,1966, Wigner Papers (ref. 68), Box 94, Folder 7; Wigner in English to Jauch, November 22, 1966, ibid., Box 71, Folder 3; Jauch in English to Wigner, October 13, 1966, ibid., Box 71, Folder 3; and Jauch to Wigner, September 16, 1966 (ref. 68).

70 Franco Selleri, "Comments on the Thesis 'A Medida na Mecânica Quântica' by K.S. Tausk," 1972, 2 pp. Personal Archive of Tausk (ref. 42).

71 Piero Caldirola, "A Geometrical Model of Point Electron," in Volume especial de julho dedicado aos "70 anos de Mário Schönberg," Revista Brasileira de Física (July 1984), 228-260; on p. 228 he wrote, "the author never forgot the precious advices received from Mario at the beginning of his scientific career in 1938 at Roma University." For a biographical note on Schönberg, see Norberto C. Fernandes, Mauro Cattani, Ivan Ventura, Kazuo Ueta, and Sílvio R.A. Salinas, "Mário Schönberg on his 70th Birthday," ibid., pp. V-VI.

72 Pessoa interviews of Tausk (ref. 28).

73 Klaus S. Tausk, "A Medida na Mecânica Quântica," Ph.D. Dissertation, Faculdade de Filosofia, Ciências e Letras, Universidade de São Paulo, 1967, 60 pp.

74 Pessoa interviews of Tausk (ref. 28).

75 Selleri, "Comments on the Thesis" (ref. 70).

76 Wigner, "Problem of Measurement" (ref. 12), p. 7.

77 Daneri, Loinger and Prosperi, "Further Remarks" (ref. 36), p. 120.

78 Wigner to Jauch, September 6, 1966 (ref. 69).

79 Jauch, Wigner, and Yanase, "Some Comments" (ref. 23).

80 O.R. Frisch, "The Conceptual Problem of Quantum Theory from the Experimentalist's Point of View," in Ted Bastin, ed., Quantum Theory and Beyond: Essays and Discussions arising from a Colloquium (Cambridge: Cambridge University Press, 1971), pp. 13-21, on p. 14.

81 Olival Freire, Jr., "The Historical Roots of 'Foundations of Physics' as Field of Research (1950-1970)," Foundations of Physics 34 (2004), 1741-1760; idem, "Quantum Controversy and Marxism," Historia Scientiarum 7 (1997), 137-152.

82 Frisch in German to Hugo Tausk, Geneva, September 16,1967, Personal Archive of Tausk (ref. 42).

83 Freire, "Historical Roots" (ref. 81).

84 Ibid.

85 Conselho Nacional de Pesquisa Process number 0208/67. In justifying the award of the scholarship, Tausk gave Mario Schönberg, José Goldenberg, and Hans Joos as his references. He also attached Bub's letter to him of November 15, 1966 (ref. 65) and a letter of invitation to him of July 28, 1966, from Vigier in Paris, where he planned to study elementary particles within Vigier's approach, specifically to "analyze the possibility of unifying the external dynamical symmetry of Elementary Particles with its internal symmetry, by introducing the De Sitter space.” Tausk's request was supported favorably by José Goldenberg, who commented on Tausk's work in Trieste: "This work of 
his on the measurement theory in quantum mechanics attracted considerable interest and, because of it, he was invited by Prof. Vigier for a period of work in Paris."

86 Sharon Traweek, Beamtimes and Lifetimes: The World of High Energy Physicists (Cambridge, Mass.: Harvard University Press, 1988), pp. 121-122.

87 Salam to Rosenfeld, September 26, 1966 (ref. 48).

88 Tausk, "Relation of Measurement with Ergodicity" (ref. 1), p. 4.

89 Bohm to Tausk, October 1, 1966 (ref. 52).

90 Bub, "Daneri-Loinger-Prosperi Quantum Theory" (ref. 66).

91 Jauch to Fonda, October 4, 1966 (ref. 53).

92 Tausk, "Relation of Measurement with Ergodicity" (ref. 1), p. 20.

93 Loinger, "Comments on a Recent Paper" (ref. 25), pp. 246-248.

94 Tausk, "Relation of Measurement with Ergodicity" (ref. 1), p. 23.

95 Tausk, "A Medida na Mecânica Quântica" (ref. 73), p. 55.

96 Pessoa interviews of Tausk (ref. 28).

97 Heisenberg, Physics and Philosophy (ref. 35), pp. 54-55.

98 Tausk, "Relation of Measurement with Ergodicity" (ref. 1), p. 32.

99 Tausk, “A Medida na Mecânica Quântica” (ref. 73), pp. 29-31.

100 P.H. Eberhard, "Bell's Theorem and the Different Concepts of Locality," N. Cim. B 46 (1978), 392-419, on 416-417.

101 A. Einstein, B. Podolsky, and N. Rosen, "Can Quantum-Mechanical Description of Physical Reality Be Considered Complete?" Phys. Rev. 47 (1935), 777-780; reprinted in Wheeler and Zurek, Quantum Theory and Measurement (ref. 2), pp. 138-141.

Departamento de Filosofia, FFLCH

Universidade de São Paulo

Av. Prof. Luciano Gualberto, 315

05508-900, São Paulo, Brazil

e-mail: opessoa@usp.br

Programa em Ensino, História e Filosofia das Ciências (UFBa-UEFS) Instituto de Física

Universidade Federal da Bahia

40210-340, Salvador, BA, Brazil

e-mail: freirejr@ufba.br

Departamento de Sociología

Centro de Estudios Sociales

Universidad Nacional de Colombia

Bogotá, Colombia

e-mail: ahdegreiffa@unal.edu.co 